\title{
La conquista de Antequera (1410). Reflexiones sobre la construcción de la memoria en la Castilla bajomedieval
}

\author{
The conquest of Antequera (1410). Reflections \\ on the construction of memory in late medieval Castile
}

\author{
Pascual MARTÍNEZ SOPENA \\ (Universidad de Valladolid) \\ sopena@fyl.uva.es \\ ORCID ID: 0000-0002-0880-7365
}

\begin{abstract}
In this paper I shall examine the memory RESUMEN: Este artículo examina la memoria de la of the conquest of Antequera by Infante Fernando, conquista de Antequera por el Infante Fernando, regent of Castile (1410). In the royal court, regente de Castilla (1410). En la corte real, chroniclers, notaries and poets collaborated in its colaboraron en su construcción cronistas, construction. The Romancero included this victory escribanos y poetas. El «Romancero» incluyó esta over the Moors among his subjects. In addition, the victoria sobre los moros entre sus temas. Pero Town councils of the Infante were associated with the además, los concejos de las villas del Infante preparation and development of the military estuvieron asociados con la preparación y campaign. Many people participated in the battle and desarrollo de la campaña militar. Muchos habitantes became anonymous diffusers of their success. participaron y se convirtieron en los anónimos difusores de su éxito.
\end{abstract}

KeYwords: Memory, Late Middle Ages, Antequera, PAlABRAS-Clave: memoria, Baja Edad Media, Castille

Antequera, Castilla

\section{INTRODUCCIÓN. LA ESCRITURA CIRCULANTE}

A comienzos del siglo XV, la Reconquista experimentó un momento de revitalización en Castilla. Se produjo durante la regencia del Infante Fernando, hijo de rey y noble principal del reino. La figura de don Fernando «el de Antequera» y su época han gozado de una atención tradicional: aunque, a renglón seguido, hay que advertir que estamos en plena renovación de los estudios históricos de ese periodo. Es una circunstancia que se ha visto estimulada por la reciente conmemoración del sexto centenario del Compromiso de Caspe, que convirtió al Infante en rey de Aragón; pero también se aprecia una corriente autónoma que, partiendo de la «nueva historia política», vuelve a valorar su «buena ventura» como regente de Castilla a través de su fortuna material y espiritual, las gentes de su casa, o la dinámica de la guerra que condujo felizmente (Nieto, 2012; Ladero, 2013; Olivera, 2013; Cañas, 2016; González Sánchez, 2016: Muñoz Gómez, 2016) ${ }^{1}$.

\footnotetext{
${ }^{1}$ Este trabajo se inscribe en los Proyectos de Investigación «El ejercicio del poder: espacios, agentes y escrituras» (ref. HAR2017-84718-B), financiado por el MINECO, y «Preinventario, sistematización, recopilación documental sobre bienes integrantes del patrimonio cultural inmamterial en las provincias de Palencia, Segovia y Soria», Junta de Castilla y León 2015-2017.
} 
Las crónicas de la época, la documentación de la cancillería real y el romancero han servido a historiadores y filólogos para analizar al hombre, su tiempo y su larga estela. En cambio, es muy escasa la atención prestada a los archivos locales. Por ello conviene indicar que la información guardada en buen número de fondos municipales ofrece nuevos puntos de vista. Destaca entre ellos la gestión de las noticias y, en una perspectiva comparada, el contraste entre los discursos de las fuentes cortesanas y concejiles. No se debe olvidar que estos ambientes forman parte de un mundo donde el volumen de la comunicación escrita se venía multiplicando desde el siglo XIII, hasta alcanzar el nivel de un rasgo cultural (Menant, 2006). Del mismo modo, se sitúan en un momento en que los datos conservados ya permiten evaluar su circulación, considerando tanto a sus actores como las formas de difusión o su velocidad (Information et Société, 2004). Para el caso, diversos archivos municipales de Castilla ofrecen posibilidades de estudiar estos problemas a través de la correspondencia que los concejos reciben de reyes, señores y oficiales. Los ecos de las reacciones que suscitaron se reflejan en las actas de las reuniones municipales y en sus cuentas. Se trata de apuntes sobre deliberaciones y respuestas, con frecuencia breves e inmediatas, donde se combinan la queja hostil y el acuerdo reverente, el mero informe y el gesto festivo.

Teniendo en cuenta estas perspectivas, las páginas que siguen reflexionan más sobre las condiciones en que se desarrolló la producción genéricamente «literaria» que sobre la propia producción. Esto es, tratan del ambiente y el contexto en que se elaboró y se difundió, lo que significa que se interesan por el proceso de construcción de una memoria «que aglutina el recuerdo que tienen de lo sucedido los contemporáneos a los hechos y sus descendientes» (Fernández de Larrea-Díaz de Durana, 2010: 10). Este interés incluye cuestiones que durante la nuestra reunión de otoño se glosaron, como la circularidad entre lo culto y lo popular, o las tareas de compilar, informar y recordar, con sus tiempos propios y sus funciones diversas. Por lo demás, esta contribución también busca acercarse a los discursos simbólicos que expresan la memoria de los hechos - mucho más que su historia-, a través de artefactos de otra naturaleza; en particular, se llama la atención sobre el legado plástico.

\section{EL INFANTE-REY FERNANDO (1380-1416) Y SUS SEÑORÍOS DE CASTILLA}

Como se adelantaba, el infante Fernando «el de Antequera» es un personaje singular en la historia española del siglo XV. Aunque fallecido prematuramente, la fama del regente de Castilla (1406-1416) y rey de Aragón y Sicilia (1412-1416), evoca sus dotes políticas, su profunda religiosidad o su proverbial codicia. Se trata de una memoria compleja, como captó su primer biógrafo (Lorenzo Valla, 2002).

Don Fernando era el hijo menor del rey Juan I de Castilla. Cuando murió su padre en 1390, recibió el Señorío de Lara. Este título vino a otorgarle la jefatura de la nobleza castellana. Al mismo tiempo, una larga lista de villas de la cuenca del Duero pasó a su poder; sobre todo se hallaban en torno a Valladolid, ya por entonces centro político del reino. De este grupo formaban parte Olmedo, Peñafiel, Cuéllar y Medina del Campo, su capital, todas ellas al sur del río, más otras situadas al norte como Mayorga.

Los recursos del Infante Fernando se multiplicaron a partir de 1395, fecha de su matrimonio con Leonor de Alburquerque. Ella también pertenecía a la parentela regia y era una «rica hembra»: es decir, una de las grandes herederas del país. Sus señoríos se diseminaban desde la frontera de Navarra a la de Portugal. Así, las villas de Villalón, Urueña, Castromonte y Villalba de los Alcores reforzaron la posición del Infante al norte del Duero y en las cercanías de Valladolid. En 1400, Paredes de Nava, otra aglomeración 
muy importante, engrosó los dominios de Fernando y Leonor en la misma zona. Al volumen de sus dominios, se añadía que la mayor parte se localizaban en regiones muy prósperas del reino, como la Tierra de Campos, la Rioja y las Extremaduras.

El infante Fernando mantuvo su status durante todo el reinado de su hermano, Enrique III. Este falleció en 1406, dejando un heredero de dos años de edad, el futuro Juan II, lo que entrañaba una larga regencia. La tarea quedó en manos de la reina viuda, Catalina de Lancaster, y del propio Infante, quien se convirtió en el gran protagonista político del periodo.

El poder y el prestigio del Infante se apoyaba en un amplio y diverso conjunto de vasallos, parientes y consejeros, formado por grandes y pequeños nobles, judíos conversos, universitarios y clérigos cultivados, más caballeros y hacendados «hombres buenos» de las villas de su señorío. Con ellos organizó una «casa» amplia y ramificada, provista de grandes recursos y disponible para ambiciosos objetivos. Su influencia se extendió fuera de Castilla; por ejemplo, tuvo como valedor al famoso dominico Vicente Ferrer, a cuya orden protegió especialmente. Todo ello favoreció su ascenso al trono de Aragón en 1412. Pero antes de que esto sucediera, la red sirvió para otros fines. Entre ellos, la organización de una larga guerra contra el sultanato de Granada, que fue presentada como una nueva «Cruzada».

Gobernado por la dinastía nazarí desde el siglo XIII, el sultanato de Granada dominaba el sureste peninsular. Era una franja de $30.000 \mathrm{~km}^{2}$, situada entre las montañas Penibéticas y el Mediterráneo, que se extendía desde el Peñón de Gibraltar hasta los secarrales de Almería. Granada ofrecía una imagen ambigua para los castellanos. Su civilización resultaba un modelo de refinamiento y excelencia técnica ante sus vecinos. En cambio, su fe musulmana los oponía. Siendo su soberano el vasallo principal del rey de Castilla y aunque desde 1350 predominaron los periodos de paz, se recelaba del sultanato como posible cabeza de puente en caso de nuevas invasiones africanas - como se venían produciendo desde fines del siglo XI. Cabe agregar que la «banda morisca», la dilatada frontera que separaba ambas monarquías, encerraba una variedad de circunstancias y tipos sociales que alimentaron el imaginario de la época, sensible a gestas heroicas y fortuna fácil.

Las campañas militares comenzaron sin brillantez en 1407, aunque revitalizaron ambiciones largo tiempo varadas. Por fin, en 1410 se alcanzó el éxito con la conquista de Antequera, una estratégica villa fronteriza (Alijo, 1983; Cobos, 2016; Peláez Rovira, 2016). Su celebración en los ambientes de la corte real — como muestran las crónicas y algún poema - , trascendió al imaginario popular; a través de los «romances fronterizos», conformó lo que se denomina «el ciclo antequerano» (Lopez Estrada, 1956; López Estrada, 1998; Correa, 1999).

\section{LA GUERRA DE GRANADA EN LA CORTE DEL REGENTE. HECHOS, RELATOS Y ARTEFACTOS}

La conocida como «Primera Parte de la Crónica del rey Juan II» está dedicada al dilatado periodo de su minoría. Se ha venido atribuyendo a Alvar García de Santa María, un miembro de la principal familia de conversos de Burgos que estuvo estrechamente vinculado al Infante. Es un texto que exalta a don Fernando y sus parciales, en detrimento de la co-regente Catalina de Lancaster y su entorno. Más de un tercio de sus páginas trata de las guerras fronterizas - especialmente, de la campaña de Antequera (Crónica de Juan $I I, 1982)^{2}$. Recientemente se ha destacado que el relato es un modelo de las tendencias de

\footnotetext{
${ }^{2}$ La corte real estuvo dividida en dos facciones contrarias. En 1408 se impuso la del Infante sobre la de su cuñada y corregente, varios de cuyos partidarios tuvieron que exiliarse. Pero la presencia en la conquista
} 
la época. Esto quiere decir que la crónica regia, convertida en oficio cortesano, se redacta casi al hilo de los hechos, utiliza fuentes diversas (desde las informaciones orales a los documentos que se iban incorporando al archivo del propio Infante), y ofrece un volumen inédito de detalles - de lo que resulta un voluminoso texto. Todo ello, junto con el dominio del arte narrativo, ha llevado a considerar este relato como la versión inmediata y oficial de la campaña de Antequera; dicho de otro modo, esta «primera parte» de la crónica de Juan II es el principal testimonio de la visión cortesana de los hechos (Bautista, 2012: 53$)^{3}$.

A lo largo de la obra, descripciones muy técnicas alternan con capítulos de intenso dramatismo y circunstancias maravillosas, donde se evidencia la común adhesión a los portentos. Hay un caso que lo ejemplifica - y que en esta contribución tendrá un notable protagonismo. El punto de inflexión del asedio de Antequera fue el combate de la Boca del Asna, nombre de un collado situado a una legua de la ciudad. Las esperanzas de los sitiados se malograron allí, al ser derrotadas las tropas de socorro enviadas por el sultán. La crónica narra la aproximación de este ejército, dirigido por dos «infantes» hermanos del soberano granadino, que acampan en el collado. Detalla después una sucesión de escaramuzas, golpes de mano, retiradas tácticas y acciones defensivas para gloria de varios paladines castellanos. El episodio concluye con la desbandada musulmana y destaca que los cristianos han conseguido la victoria milagrosamente, considerando la enorme diferencia de número de los combatientes. Tras ello, una noticia muy precisa informa de que el Infante mandó cartas a la reina regente y al rey-niño, así como a las ciudades y villas notables del reino, para comunicarles «la buena andanza que Dios les diera en esta pelea», y su gratitud a la Virgen María, «cuyo caballero él era»; no se olvidó de señalar en las misivas que la batalla se había dado en cierta festividad de San Juan Evangelista, otra feliz coincidencia (Crónica de Juan II: 300-309) ${ }^{4}$.

Es interesante constatar que Alfonso Alvarez de Villasandino ya había saludado la fortuna del Infante recién acabada la campaña. Todavía no era «el rey Fernando de Aragón» - aunque ya lo pretendía-, cuando el conocido poeta de la corte de Castilla ensalzó la victoria de la Boca del Asna. En sus versos evocaba a los dos «infantes» granadinos derrotados, la ayuda de la Virgen María y la orden de caballería que don Fernando había fundado en su honor, la intervención del patrono de las Españas, Santiago, y la de San Juan Evangelista...(Cancionero de Baena, 1966, I: 22-26). Las concordancias de su poema con la crónica y con las cartas enviadas a los concejos por el regente, reflejan un discurso común desde el principio, adaptado a fines y públicos diversos.

de Antequera de los más importantes (Juan de Velasco, Diego López de Stúñiga), refleja su regreso, una vez reconciliados con el Infante.

${ }^{3}$ En este sugestivo artículo, Francisco Bautista también discute que la citada crónica sea obra de Alvar García, aunque no duda en afirmar que su autor formaba parte del círculo más próximo a don Fernando.

${ }^{4}$ El texto combina el relato de los hechos con la percepción de los portentos. Así, se cuenta que los moros componían una fuerza de 3000 peones y 1000 «lanzas» (cada «lanza» equivalía en Castilla a un caballero y dos o tres sirvientes), y los cristianos que entraron en combate no habían pasado de 200; mientras solo 10 o 12 de estos cayeron en la refriega, fue incontable el número de sus enemigos muertos y presos. Bajo semejante signo, el Infante mandó a los súbditos del reino que se hicieran procesiones solemnes en agradecimiento a Dios y a la Virgen «por este buen acaesçimiento que me dio». La crónica incorpora como modelo la carta de don Fernando a la ciudad de Sevilla, donde se proclama que la victoria «plogo a Dios y a la Virgen Santa María, y al señor San Juan, cuyo día es hoy»; en efecto, la fecha del combate sirve de refuerzo al factor providencial (el 6 de mayo se celebra la festividad de San Juan ante Portam Latinam, conmemorativa del suplicio de san Juan Evangelista en Roma, al que sobrevivió). El Infante también pedía al concejo que a su criado Manuel Xerez, que hizo de mensajero, le fueran dadas «albricias» (del árabe hispánico al-búsra, «recompensa por dar buenas noticias»). 
Como parte del mismo discurso, a las circunstancias de tono providencial se agregan varios elementos simbólicos a los que la Crónica da un sentido político que es posible contextualizar. Algunos de ellos permanecen hoy en los sitios donde estaban en 1410 , pero sobre todo siguen formando parte del imaginario local.

La devoción del Infante a la Virgen María ya ha sido resaltada. No era una cuestión menor. En 1403, viviendo aún su hermano Enrique III, el Infante había promovido la fundación de la orden de caballería «de la Jarra y el Grifo» (Muñoz Gómez: 133-139). Esta orden se pretendía heredera de otra legendaria, vinculada al monasterio de Santa María la Real de Nájera y al recuerdo de su fundador, el monarca navarro García Sánchez III (1035-1054) ${ }^{5}$. Lo cierto es que en este lugar, panteón de su dinastía y de varias parentelas nobiliarias, se conjugaba el culto a una imagen mariana, cuyo hallazgo supuestamente milagroso dio origen al cenobio, con la memoria de la incorporación de La Rioja a Castilla en 1076, tras el asesinato de Sancho IV, hijo y sucesor de García Sánchez. Tres años más tarde, el rey Alfonso VI lo donaba al monasterio de Cluny, que hizo de esta casa una de sus principales sedes en España (Reglero, 2008: 152-153).

El cronista destacó que el Infante había hecho traer a su campamento sendas preseas desde León y Sevilla que cabe calificar de reliquias, pues se relacionaban con antiguas y prodigiosas victorias de los cristianos sobre el Islam. Ambas son mencionadas en diversos pasajes, entre ellos la triunfal entrada en Sevilla a la vuelta de la campaña (Crónica de Juan II: 129-131, 190-191 y 400). Una era la espada «Lobera» de Fernando III, el rey que había conquistado gran parte de Andalucía a mediados del XIII, cuya fama santa mereció su canonización mucho más tarde. Se guardaba (y se guarda), en la catedral de Sevilla - la ciudad que resume su victoria y el sitio donde está su tumba (Muñoz Gómez, 2016: 150-1516). La otra, el pendón de San Isidoro, fue llevada desde su abadía de León. Lo más relevante de esta pieza - también conservada en la propia abadía hasta hoy-, es el gran bordado que muestra al patriarca de la iglesia visigoda sobre un corcel, revestido de las insignias episcopales y armado de espada y cruz preciosa. La escena recogía una tradición según la cual el santo se había aparecido al emperador Alfonso VII cuando sitiaba la ciudad de Baeza (1147), para anunciarle su conquista (Montaner, 20097). El pendón de San Isidoro ondeó en la alcazaba de Antequera en cuanto fue tomada. Al

${ }^{5}$ La orden fue fundada el día de la Asunción de 1403 en la villa de Medina del Campo. Al año siguiente celebró capítulo en Santa María de Nájera. En tiempos recientes, se han producido iniciativas (distintas) en ambas ciudades para restaurar esta orden, que en La Rioja enfatiza la leyenda de García Sánchez y en Medina del Campo celebra a Fernando el de Antequera.

${ }^{6}$ La crónica describe la liturgia de entrega y devolución de la espada «Lobera» en la antigua «Capilla de los Reyes», donde estaban enterrados Fernando III, su esposa Beatriz de Suabia y su hijo Alfonso X. Sus restos siguen en la actual capilla, obra del siglo XVI, así como la imagen de la «Virgen de los Reyes», que también proviene de la primitiva. En cambio, se perdieron hace siglos las estatuas sedentes de los monarcas; la del rey Fernando portaba su espada, y el ritual con que primero se cedió y luego se repuso el arma fue el centro de las ceremonias. En Sevilla se conmemora cada 23 de noviembre la conquista de la ciudad, y la «Lobera» preside la procesión religioso-cívico-militar que recorre la catedral.

${ }^{7}$ Dejando aparte sus orígenes inciertos, la leyenda se documenta en la primera mitad del siglo XIII, entre los Milagros de San Isidoro de Lucas de Tuy. Es posible que ya estuviera asociado a una cofradía de caballeros, de trayectoria desconocida. En cambio, parece seguro que la leyenda reverdeció en el siglo XIV; el gran pendón es su señal más expresiva, así como la instauración o restauración de la cofradía. A tener en cuenta que esta versión militar e inédita del santo confesor se asocia con la muy frecuente de Santiago «matamoros»; en efecto, un bordado menor del propio pendón muestra el brazo armado del Apóstol emergiendo entre nubes. El domingo más cercano a la festividad de San Isidoro (26 de abril) tiene lugar en León la ceremonia «de Las Cabezadas», una discusión retórica entre el ayuntamiento y la abadía sobre si es «foro» (obligación) u «oferta» (devoción) la entrega ritual de cirios por el primero a la segunda; la disputa, presidida por el pendón de San Isidoro, acaba en tablas. 
cabo de unos días protagonizaba la mencionada entrada en Sevilla, junto con la «Lobera», los pendones de la Cruzada, del Infante y de los ricos hombres que habían participado en la campaña.

Del orden de lo prodigioso forman parte otros hechos que festonearon la campaña porque fueron interpretados como signos proféticos. Así, el cronista recoge que en la galera capitana de la flota que vigilaba el estrecho de Gibraltar mientras duró la contienda - a fin de estorbar o avisar de la llegada de auxilios desde Marruecos-, los marineros habían visto por dos veces «el cuerpo santo de frey Pedro González, con candelas ardiendo, en la popa e ençima del pendon», lo que se consideró como un buen presagio (Crónica de Juan II: $374^{8}$ ).

Si tales objetos y signos habían servido para enardecer a las tropas sitiadoras y a su caudillo, el éxito militar reforzó su propio carisma. Antes habían sido elementos de naturaleza y trayectoria dispar, cuya irradiación no debió rebasar ámbitos locales —en los que hoy siguen prosperando con elementos más o menos antiguos y pintorescos. Pero en los tiempos de Antequera, su uso sagrado y simultáneo, solemne y público, a modo de insignias del ejército cristiano, los revitalizó al mismo tiempo que les confería una imagen unitaria que nunca habían tenido. Su incorporación a la crónica reflejaba la voluntad de insertar las campañas del Infante en una construcción que conjugaba la guerra y lo sagrado.

Esta suma de narraciones, de tradiciones que se revitalizan y de preseas sacralizadas, con las virtutes que las hacían necesarias y las explicaban, se sustentaba a comienzos del siglo XV en cierto número de relatos breves pocas veces aislados. Sus versiones podían estar insertas en crónicas como la Najererense del siglo XII (Chronica Hispana 1995), en cendones como los Milagros de San Isidoro del XIII (Lucas de Tuy ca. 1230/1525), aunque también se expresaban mediante leyendas taumatúrgicas menos formalizadas. Pero tanto en estos casos como en las piezas que fue reuniendo el autor de la Crónica de Juan II para una historia minuciosa de la campaña de Antequera en la tierra y el mar, se aprecia un carácter de «unidades elementales» provistas de autonomía (Garcia, 2010: 34). El relato del combate de la Boca del Asna o el asombro antes los fuegos de San Telmo hubieran podido no figurar en la Crónica sin por ello desmentir el sentido de la narración. Más bien explica su inserción un deleite de contar, de multiplicar las ocasiones amenas y educativas, en loor de su protagonista, el Infante-Rey.

\section{DOS VILLAS DE LA RETAGUARDIA Y SU CONTRIBUCIÓN A LA CAMPAÑA DE ANTEQUERA}

Las villas de Villalón y Paredes de Nava se hallan a más de 700 km. de Antequera. Una y otra ocupaban una posición destacada en la Castilla del Duero a comienzos del

\footnotetext{
${ }^{8}$ Se trata del fenómeno de electricidad estática conocido como «fuego de San Telmo» en el mar: «[...] corrieron tormenta las fustas que iban con Juan Enrriquez, e dicen los de su galea que vieron esa noche el cuerpo de frai Pedro González, con sus candelas, como la otra bez» (Crónica de Juan II, 375). Juan Enríquez, bastardo del almirante Alfonso Enriquez, se encargó del bloqueo de la costa del estrecho durante la campaña (véase nota 23). Estos rayos azules que en las tormentas chocan con los mástiles de los navíos, eran percibidos en España como signos propicios del venerado dominico Pedro González «Telmo», un fraile natural de Frómista, en Tierra de Campos, fallecido en 1246, que acompañó a Fernando III en las primeras campañas andaluzas y predicó entre las gentes de mar — por quienes era invocado, aunque su canonización data del siglo XVIII. En realidad, en España se trasfirió al fraile Pedro González cierta cualidad atribuida a San Erasmo o «Elmo», mártir antiguo y patrono de marineros en Italia, cuyo culto se asocia desde mucho tiempo atrás con el fenómeno descrito; como es patente, la adaptación hispana incorporó el propio nombre del mártir, bien como sobrenombre o incluso sustituyendo al del fraile. La fiesta de San Telmo se celebra en Frómista por la octava de Resurrección; su momento culminante es la «procesión cívica del Ole».
} 
siglo $\mathrm{XV}$, según lo que el monto de su tributación sugiere sobre el número de sus habitantes. En 1409, su cuantía fiscal situaba a Paredes de Nava en el cuarto puesto entre las poblaciones del sector nororiental del valle, en tanto Villalón ocupaba el noveno. Es decir, ambas se situaban entre las mayores aglomeraciones de la zona tras Burgos, Valladolid y Palencia, las capitales políticas, económicas y eclesiásticas del territorio (Reglero, $1995^{9}$ ). Que ambas villas formaran parte del señorío de don Fernando, entre otras de las mayores del área, da cuenta del peso específico del Infante.

Las dos villas distaban entre sí dos jornadas cortas y estaban situadas en el centro de la Tierra de Campos, una llanura suavemente ondulada que abarca unos $7500 \mathrm{~km}^{2}$. La región venía dedicándose secularmente al cultivo de los cereales y el viñedo; además, criaba una nutrida cabaña ovina. Desde el siglo XII, sus excedentes eran exportados a la fachada atlántica, animando un activo comercio interregional. Pues en torno a 1400, la Tierra de Campos era la región más rica y poblada del valle del Duero. Sobre un semillero de aldeas, una red de «pequeñas villas» articulaba el poblamiento de la zona. Eran una treintena, cada cual con cientos de vecinos; según los cálculos más ponderados, las cifras locales oscilaban entre 1000 y 4000 habitantes. Muchas de ellas extendían su jurisdicción sobre amplios territorios y otro de sus rasgos característicos era la celebración de mercados semanales. Aunque existía un artesanado elemental (e incluso se intuye cierta especialización textil), estas aglomeraciones recuerdan a las «agrovillas» italianas.

Por otra parte, se trataba de una región donde las ambiciones de los señores se enfrentaron a una larga tradición municipal, lo que dio lugar a episodios de violencia. Paredes de Nava fue escenario del más conocido. Tras larga guerra civil, el conde Enrique de Trastámara se había convertido en rey de Castilla en 1369; este monarca, hijo bastardo de Alfonso XI, es apodado «Enrique el de las mercedes» por la prodigalidad con que repartió villas y tierras entre los nobles que le habían aupado al trono. En este contexto, el vecindario se levantó contra su decisión de ceder el señorío de la villa a su cuñado, Felipe de Castro. Quien en 1371 pereció en una emboscada de sus revoltosos vasallos, lo que supuso una severa represión conducida por otros señores del país, así como el pago de una elevada multa (Martín Cea, 1992: 50).

Esto no obsta para subrayar que Paredes de Nava creció sensiblemente entre 1386 y 1410; en ese cuarto de siglo, se estima que el número de «hogares» fiscales pasó de 716 a 840, lo que supone un mínimo de 3000 almas. La villa estaba dividida por partida doble: entre las cuatro parroquias o «collaciones», y entre ocho barrios, a los que se sumaba la Judería hasta 1412. No eran solo divisiones eclesiásticas y territoriales, como sugieren los términos, sino que ambas categorías también servían a efectos fiscales y de gobierno (Martín Cea, 1992: 31, 35-36 ${ }^{10}$ ).

\footnotetext{
${ }^{9}$ Este estudio analiza los datos de la contribución de 1409 al «pedido» (el principal impuesto regio acordado por las Cortes de Castilla). Anota las sumas repartidas entre 1600 aglomeraciones, dentro de un área de $25000 \mathrm{~km}^{2}$ que afecta a las actuales provincias de Burgos, Palencia, Valladolid y Zamora.

${ }^{10}$ Paredes de Nava celebraba su mercado semanal los viernes. Los barrios eran la base de la fiscalidad concejil (que incluía los impuestos llamados «fumazgos» — base del cálculo demográfico—, las «derramas»y los «repartimientos» sobre bienes muebles y raíces); las parroquias se utilizaban para la fiscalidad real («monedas»). En 1410 se aprecia un descenso puntual del número de contribuyentes, que Martin Cea explica por el servicio de armas que numerosos vecinos debieron prestar al infante en la campaña de Antequera (véase después); cuantos participaron, fueron eximidos temporalmente de tributación. También estima que había un número indeterminado de hogares exentos (por ser de hidalgos, clérigos o pobres), para agregar al número de hogares contribuyentes o «pecheros» (que podían ser «enteros», «medios», etc., según pagaran toda la contribución o una parte variable). Como consecuencia de la crisis antijudía que había incitado fray Vicente Ferrer con el concurso del Infante, la judería de Paredes desapareció en 1412. Desde la perspectiva institucional, los 4 alcaldes correspondían a las parroquias y los
} 
Villalón también poseía cuatro parroquias, aunque su población debía ser algo más reducida que la de Paredes ${ }^{11}$. A efectos fiscales estaba dividida en seis «quartos», siguiendo un modelo bastante común en las villas de la región desde la primera mitad del siglo XIV. La iglesia principal era San Miguel «del mercado». Fundado por el rey Alfonso VIII (1159-1214), el mercado semanal se celebraba los sábados (Duque, 2006: 31). Una disposición de 1410 subraya la presencia de merchanes que bajaban de «la Montaña» con carretas y recuas de mulas a comprar cereales. La importancia del tráfico de granos de la Tierra de Campos hacia las regiones deficitarias del norte (muchos de cuyos habitantes se dedicaban a la arriería), queda subrayada por la fecha del documento, a comienzos del otoño, que refleja el momento de proveer las despensas para el largo invierno ${ }^{12}$. El ritmo del comercio agrario es revelado por otros indicios que denotan un marco de privilegios y negociación. El Infante Fernando, fundador del convento de Santo Domingo de Villalón, había concedido a los frailes el derecho de «estanco» del vino durante el mercado extraordinario que se celebraba el día de San Juan ( 24 de junio). Para las villas de la Tierra de Campos, esta fiesta de comienzos del verano significaba una gran posibilidad de vender el sobrante de la cosecha anterior a precios relativamente altos. Su destino era el mercado del norte, también deficitario en vino ${ }^{13}$.

Entre agosto de 1409 y diciembre de 1410, las actas de las reuniones del concejo de Villalón tienen como tema central la campaña de Antequera, al igual que debió suceder en Paredes de Nava (donde, a falta de actas conservadas, la información principal proviene de las cuentas municipales). Su primer testimonio es la copia de una carta del infante Fernando, remitida desde Paredes. Su preámbulo sobre la decisión de hacer la guerra a los moros de Granada, «enemigos de la santa fe católica», incluye el anuncio de la nueva campaña para el año siguiente, «por la salvación de la fe, el servicio del rey, y el provecho, la defensa y la expansión de sus reinos». Las gentes de Villalón - recuerda—, saben que su señor ha evitado sobrecargarles de impuestos, para que creciera su población y por lo mucho que ya pagaban a la hacienda regia. Pero ahora, la situación exige a todas las villas del señorío un esfuerzo particular. Villalón tiene asignada una suma de 85.500 maravedíes, a recaudar en dos breves plazos antes del final del año ${ }^{14}$.

Pero los retrasos en el pago de esta contribución extraordinaria y de la del año siguiente, fueron un dato común en las sesiones de todo el periodo; además, se conjugaban con el impago de los impuestos votados por las Cortes. En realidad, la secuencia de retrasos remonta al año 1407, como mínimo. Los recaudadores del Infante emplearon tonos cada vez más amenazadores frente a una comunidad que primero se manifestó con

8 regidores, a los barrios. Aquellos primeros representaban la organización administrativa y judicial antigua, que se fue difuminando en el siglo XV. Los regidores tomaron a su cargo las funciones de gobierno una vez se consolidó el señorío del Infante Fernando.

${ }^{11}$ Archivo Municipal de Villalón (= AMV), Primer Libro, sesión 16.11.1410. Una carta del concejo ordenando que se paguen 2400 maravedíes de la «martiniega» al monasterio de Santo Domingo, a razón de 4 maravedíes por casa, sugiere que la villa contaba con unos 600 hogares de vecinos contribuyentes o «pecheros».

12 AMV, Primer Libro, sesión 07.10.1410.

${ }^{13}$ Se conocía como «estanco» el derecho a la venta exclusiva de un producto, durante un periodo preciso y hasta el fin de las existencias. Es patente que en este caso, los vecinos de Villalón se veían perjudicados, lo que condujo a un pacto. El concejo negoció con el convento una compensación por la renuncia temporal a este privilegio (AMV, Primer Libro, sesión 13.09.1409). Es oportuno recordar que Villalón de Campos se convirtió en sede de dos grandes ferias desde los años 1430. Una se celebraba durante la Cuaresma, mientras la otra se iniciaba por San Juan y duraba un mes (Duque, 2006: 45); cabe suponer que esta derivó del citado mercado extraordinario.

${ }^{14}$ AMV, Primer Libro, sesión 24.08.1409. 
tibieza, y luego expresó su rechazo... Sin embargo, la fase aguda del conflicto se cerró con la sumisión del concejo a fines de $1409^{15}$. No había sido un fenómeno aislado. Los oficiales del regente emplearon los mismos tonos contra las principales villas de su señorío en la región — conminando a los concejos de Paredes de Nava, Saldaña y Mayorga.

Además, la guerra exigió levantar tropas en los señoríos del Infante. La preparación de la campaña de Antequera tiene una fecha precisa y temprana en Paredes de Nava. A principios de febrero de 1409, seguramente bajo la supervisión del Infante, Diego Rodríguez Zapata se había desplazado a la villa para organizar el «alarde» del vecindario, que se celebró el día 26 del mismo mes ${ }^{16}$. Este acto no debió ser solo la verificación del «estado de fuerzas»; quizá se hiciera una selección de los ballesteros y lanceros de la milicia concejil, aunque la leva se demoró largamente.

Pues no fue hasta noviembre de 1409 que se recibieron las órdenes de alistamiento en las villas y lugares del señorío. A Paredes de Nava se le asignaron 30 ballesteros y 60 lanceros (Martín Cea, 1992: 51-52), y a Villalón, 25 ballesteros y 33 lanceros ${ }^{17}$. Es visible que representaban una proporción significativa de los habitantes de ambas villas. Como se precisa en la carta dirigida a Villalón, debían ser «hombres jóvenes, aptos para armar y tirar con ballesta, así como para manejar lanza y escudo, y pelear si fuera necesario». Se les prometía un buen salario, «para que tuvieran mejor voluntad de servir como buenos y leales vasallos». A fin de seleccionar quiénes formarían el contingente, fue entonces cuando el concejo ordenó el correspondiente alarde ${ }^{18}$.

Las milicias partieron en la primavera de 1410, al tiempo que se formalizaba el sitio de Antequera. Don Fernando había dispuesto que recibieran al salir el salario de un mes como adelanto. Los tributos que sus villas debían recaudar para la hacienda real este año, se iban a derivar a ese fin. Pero a comienzos de julio todavía no se había pagado nada, y desde el campamento del Infante se urgió el envío de las sumas previstas. Semanas después, una nueva instrucción ordenaba que el concejo de Villalón se encargara de cosechar el grano y labrar las viñas de los combatientes; su coste se repartiría entre los otros habitantes.

Precisamente a fines de agosto de 1410, llegaban a Villalón ciertas noticias sobre el descontento del ejército sitiador. Quizá suavizadas, pues trasmitían que el Infante Fernando ya había tomado las mejores medidas para resolver la situación. Resultaba que las milicias de ballesteros y lanceros se habían quejado de que, con tan larga campaña, sus haciendas se estaban perdiendo. Le habían pedido retornar a sus lugares, a lo cual él había accedido. Por tanto, mandó a las villas de su señorío que prepararan el relevo. Otros tantos hombres debían ser reclutados en el menor plazo posible. Esta vez, recibirían de

${ }^{15}$ AMV, Primer Libro, especialmente sesiones 25.08.1409, 13.10.1409 y 04.12.1409.

16 «Alarde», del árabe hispánico al-ard, la revista militar a la que concurrían los hombres de un lugar con sus armas.

${ }^{17}$ En adelante, los términos «ballesteros» y «lanceros» alternarán con el más genérico «infantes», pues las milicias se componían de tropas «de infantería»; en los textos no aparece un término tradicional, «peones». También fueron movilizados los «caballeros» de las villas, que formaban un contingente reducido e independiente de vasallos del Infante; algunos de Villalón habían salido a campaña en octubre de 1409. (Duque, 2006: 44). Se confía haber evitado la confusión entre el uso de «infante» como significativo de hijo y hermano de reyes (para don Fernando, alguno de sus parientes o los «infantes de Granada»), y el que designa a los miembros de las milicias concejiles.

${ }^{18}$ AMV, Primer Libro, Sesión 07.11.1409. El concejo acordó — con sorprendente celeridad—, que el «alarde» tendría lugar al día siguiente. Debían acudir todos los vecinos varones, de los adolescentes a los ancianos, portando las armas que les correspondían según su calidad de «ballesteros» o «lanceros»; ambas categorías de infantes diferenciaban a los vecinos según su capacidad económica y fiscal. 
sus concejos dos meses de paga al salir, y se enviaría el importe de un tercer mes al campamento. Todo iría a costa de los ya citados «pedidos»; si no bastaban, se ordenaba repartir lo restante entre los vecinos.

En efecto, se formó un segundo contingente en ambas villas. El de Paredes fue algo menor que el anterior: 25 ballesteros y 45 lanceros acudieron a reunirse con el resto de las milicias concejiles en Medina del Campo, hasta donde los acaudilló Toribio Fernández Valiente, un destacado miembro del concejo (Martín Cea, 1992: 51-52). No sabemos su fecha de partida - a diferencia de los de Villalón, despedidos el 23 de septiembre de 1410. Pero tampoco sabemos si esta tropa pasó de Medina del Campo. Ese mismo día, un correo del Infante salió de la capital de su señorío en dirección a Villalón, para anunciar que Antequera había sido tomada el día 17.

\section{ENTRE LAS EMOCIONES DE LA GUERRA Y LAS REDES DE RELACIONES}

Los primeros compases de este trabajo se hacen eco de una visión de la baja Edad Media como «un mundo en que lo escrito domina todos los campos de la vida» (Menant, 2006: 33). Viene a confirmarlo la variedad de textos que festonean la campaña de Antequera. Se trataba de crónicas, poemas y «escritura documental», que solían proceder de ambientes cortesanos y con frecuencia se interpretaban a escala local; que podían tener carácter de noticias urgentes o vocación de memorias; y que a veces se asociaron con objetos carismáticos o supuestas circunstancias maravillosas. Desde los privilegiados observatorios de Paredes y Villalón de Campos, la guerra se vivió intensamente y con sentimientos ambiguos. Órdenes y noticias constantes hicieron que la vida local pivotara sobre la campaña, provocando emociones contradictorias.

Oficialmente, el concejo añadía a las celebraciones religiosas las manifestaciones festivas: no podía ser de otro modo, pues la retaguardia se mantuvo informada sobre una versión de la contienda que asociaba buen orden, notable colorido y grandes portentos. Corría el vino al despedir a los milicianos, y la lidia de toros acompañaba a los éxitos militares. A principios de 1410 se habían dado instrucciones para que ballesteros y lanceros se concentraran en Córdoba el 20 de marzo; un mes antes, los lanceros de Villalón ya disponían «de un pendón, e que fue pintado de las armas del dicho concejo porque fuesen conoscidos», al estilo de lo que habían hecho todas las villas y lugares que iban a concurrir. Cuando acababa abril, el concejo conoció por una carta de la infanta Leonor que se había alcanzado una gran victoria, en la que «murieron más de veinticinco mil moros y solo tres cristianos por gran maravilla de Dios». Aún más abultada es la noticia puntual de un nuevo combate, que corresponde al de la Boca del Asna. En el acta de la reunión concejil del 19 de mayo, se trascribió otra carta que narraba cómo «vinieron dos infantes del rey de Granada con cuatro mil de a caballo y cincuenta mil de a pie, muriendo cinco mil moros y resultando heridos tres cristianos» (Duque, 2006: $44^{19}$ ).

En contraste, la guerra representaba una requisa constante de recursos materiales y humanos. Según parece, la contribución de los vecinos de Paredes al cerco de Antequera devastó el erario municipal. El concejo pagaba el salario de lanceros y ballesteros, a 6 y 8 mrs. diarios respectivamente - al igual que en Villalón. A esta carga había que añadir los 200 mrs. que cada combatiente recibió al salir de la villa, y su exención temporal del pago de ciertos impuestos municipales (los fumadgos) y regios (las monedas) (Martin Cea, 1991: 51-52). En Villalón, una situación similar llegó a movilizar a los vecinos

${ }^{19}$ Las cuentas municipales de Paredes de Nava se hacen eco de la victoria en clave festiva: «Por este motivo organizaron una corrida especial de toros 'quando venieron las nuevas buenas de commo el Infante ouiera buena ventura e vençiera a los moros que venían descercar a Antequera» (Martín Cea, 1991: 52). 
contra su señor. Es plausible que en el círculo del Infante temieran una reacción de gran envergadura. La actitud de rechazo les previno contra una revuelta que reeditara la de 1401, cuando los vecinos se rebelaron (sin éxito) contra el nuevo régimen de gobierno impuesto por don Fernando, cuya clave era la designación de seis «regidores» perpetuos $^{20}$.

Naturalmente, los regidores eran hombres del Infante (Duque, 2006: 45). Habían sido reclutados en la villa, en la comarca y más lejos, o en los estudios universitarios. No fue raro que vecinos hacendados de una villa sirvieran al Infante en la otra ${ }^{21}$. Todavía en el año 1409 se mantenían en Villalón la mitad de los nombrados en 1401. Dos de ellos, al menos, compatibilizaban el cargo con otras funciones dentro del aparato de poder de don Fernando. Uno era Pedro Fernández Cabeza de Vaca, miembro de una antigua parentela noble de la comarca y alférez del Infante — es decir, un jefe de su mesnada. El otro, Día Sánchez de Basurto, era el recaudador del tributo extraordinario que suscitó el rechazo de sus convecinos. Además, el nivel local tenía su correlato a escala de la Tierra de Campos, donde el Infante contaba con poderosos aliados. Los mejores ejemplos son Alfonso Enríquez, Almirante mayor de Castilla desde 1405, y Sancho de Rojas, por entonces obispo de Palencia. El papel de esta ciudad como frecuente sede del Infante se asocia a su intimidad con el prelado (Villarroel, 200322). En cuanto al Almirante, pertenecía a la parentela real; era tío del Infante y había sido su canciller mayor. Desde 1389 y por espacio de cuarenta años, este ricohombre construyó un gran señorío en la zona cercana a Villalón y Mayorga. Medina de Rioseco fue su capital (Martínez Sopena, 1977).

Mientras ambos regidores jugaron en la campaña el papel que sus cargos sugieren, el obispo acudió al sitio de Antequera, destacando en el combate de la Boca del Asna. Por su parte, el Almirante era responsable del bloqueo del estrecho de Gibraltar - tarea que delegó en su hijo Juan Enríquez. Aún más sugerentes son los indicios de articulación de la plataforma social del Infante en la región ${ }^{23}$.

Pero la valoración de la guerra demanda otros matices. Las cartas de pago de los 58 miembros del primer contingente de Villalón muestran que todos regresaron, lo que por una vez daría la razón a quienes buscaban signos providenciales. La suma que se les

${ }^{20}$ AMV, Primer libro, sesión 23.10.1409. Los regidores hicieron releer y copiar una carta conminatoria del Infante al concejo, fechada el 25 de julio de 1401. Fue una medida disuasoria para recordar a los vecinos que antaño ya habían fracasado frente a su señor. Como se aprecia, los cambios de gobierno local se produjeron simultáneamente en Paredes y Villalón. Esto supuso que muchos actores foráneos se incorporaran de un plumazo a la política local; factor tradicional de rechazo, siempre se había procurado dosificar.

${ }^{21}$ Así, Juan Fernández del Moral, vecino de Villalón, fue nombrado corregidor de Paredes; su gestión provocó un pleito con la villa ante la corte del Infante (Martín Cea, 1991: 51). O en 1409, el tesorero mayor del Infante se llamaba Juan García de Paredes (AMV, Primer Libro, sesión 20.02.1409); a sus órdenes estaba Día Sánchez de Basurto, que se mencionará de inmediato.

${ }^{22}$ En 1409, la fiesta de San Andrés, patrono personal del Infante, se iba a celebrar en Palencia con un convite; por ello, su despensero pidió que se enviaran 70 pares de gallinas desde Villalón (AMV, Primer Libro, sesión 26.11.1409). Principal aglomeración de la Tierra de Campos, Palencia era una ciudad de tradición textil.

${ }^{23}$ Así, un hermano de Día Sánchez de Basurto (cuyo apellido señala orígenes vizcaínos) era canónigo de la catedral de Palencia. A las órdenes de Juan Enríquez, «capitán mayor» de la flota, comandaron galeras algunos nobles de la Tierra de Campos como Alvar Nuñez Cabeza de Vaca, miembro de una parentela mencionada en relación con el Infante, y Pedro Barba, señor de Villavicencio (Martínez Sopena, 1999). Habría que investigar si existe alguna relación entre tales «patrones de tierra adentro» y cierta obligación características de numerosos señoríos de behetría de Campos: el servicio de «galeotes» —es decir, como tripulantes de galeras_-, que se convirtió en un tributo en el siglo XV (Estepa, 2003, II: 339-349). 
pagó, 23.880 maravedíes, indica que la campaña proporcionó grandes ingresos a gentes comunes. Los altos salarios pudieron ser una forma de recuperar los costes que representaban los tributos (González Sánchez, 2016: 65): de suerte que la guerra del Infante también sirvió para generar y redistribuir recursos a escala local (aunque fuera una escala muy inferior a los ambientes privilegiados). Todos estos elementos contribuyen a explicar la trascendencia social de la conquista de Antequera.

\section{EPÍLOGO. EL RETABLO DEL ARZOBISPO Y EL REY}

Vale la pena recordar las secuencias de difusión de los hechos de Antequera. Menos de dos semanas después del Combate de la Boca del Asna, desde Sevilla a la Tierra de Campos se habían trasmitido las mismas noticias que, en un estrecho decenio, sirvieron a Villasandino para festejar con su poema al Infante Fernando y que adquirieron en la Crónica de Juan II una forma literaria más extensa. Luego, como López Estrada destacó, la materia - ampliada con los lances de una plaza de frontera que atravesó en precario el siglo XV-, se renovó a través del romancero, fue glosada en los primeros capítulos del Quijote y cruzó el Océano, recreándose en el Perú del siglo XVII. En suma, la conquista de Antequera no fue un éxito lejano y momentáneo en la frontera de Granada. Dio lugar a una memoria inmediata y colectiva, sostenida por las noticias oficiales y las vivencias de los muchos que participaron, además de los otros y diversos efectos que tuvo a escala local. Desde entonces y después, sobre una trama común actuaron lectores y escritores, cantores, rapsodas y escuchantes que siguieron recreando emociones, hasta convertirlas en tradición oral y hasta trufar con ellas la mejor literatura o la más prolija.

Angus MacKay escribió que los romances fronterizos son por lo común romances «noticieros», que se basan y relatan episodios de la frontera (MacKay, 1988). Tiene mucho interés su reflexión sobre la circularidad entre los romances, propios de la «pequeña cultura», y las crónicas, expresión de la «gran cultura», porque sugiere que es difícil generalizar si fueron antes unos u otras. Por el contrario, definió con rotundidad que la temática caballeresca de los romances lleva a pensar en un género nacido en linajes y bandos concretos, encargado a ministriles para honra de la casa, y que su nacimiento y expansión se produjo en la frontera y para consumo de la sociedad de la frontera. No parece bastante. Para el caso, conviene conjugar la irradiación del Infante por toda la corona, con la proximidad de la crónica a los hechos que narran la conquista, así como de estos a cualquier otro relato - desde los poemas cortesanos a la correspondencia señorial. Y conviene conjugarlo con un amplio despliegue de elementos simbólicos, presentados como reliquias históricas revividas. Además, se hace preciso valorar la presencia de tanta gente de las villas de su señorío en la campaña: caballeros que compartían su condición de vecinos notables y sus relaciones directas con el infante, ballesteros de cierta cuantía, lanceros más modestos. Todo lo cual hace pensar que los caminos de la difusión fueron intensos e inmediatos, y que en ellos participaron activamente las sociedades locales.

De la trasmisión de noticias a las memorias de los hechos, hay una variedad de relatos y un proceso de decantación complejo; piénsese en los ambientes de corte y los concejos, en la distancia del oficio de cronista de la guerra al deber de los vasallos; y dentro de estos, el reflejo sutil de «grupos-que-no-suelen-hablar».

Como también ha quedado indicado, memoria y tradición son conceptos poliédricos, que a través de sus formas breves y más concretas proponen fuertes nexos entre las expresiones escritas y las plásticas. En este sentido, cabe una ilustración final.

En una de las salas del Museo del Prado dedicadas a la pintura medieval se exhibe el primitivo retablo mayor del monasterio de San Benito el Real de Valladolid. La obra 
se atribuye al pintor Juan Rodríguez de Toledo y se debe al mecenazgo de Sancho de Rojas, que en 1415 fue promovido al arzobispado de Toledo. Probablemente fue realizada en torno a 1420 y por espacio de un siglo permaneció en su sitio original. Luego fue desplazado a otro lugar de la iglesia, antes de acabar en San Román de Hornija, una de las muchas dependencias del monasterio vallisoletano. El retablo sufriría avatares diversos hasta que en 1929 pasó a la gran pinacoteca donde luce ${ }^{24}$.

Juan I había fundado San Benito en 1389, cediendo a la comunidad su propio alcázar de Valladolid. Según los propósitos del monarca, el cenobio debía combinar sus afanes de reforma eclesiástica con el deseo de que la Providencia velara por el buen gobierno del reino - todo mediante las oraciones y penitencias de los religiosos. Cuando se fabricó el retablo, el monasterio no había alcanzado la condición de cabeza de los benedictinos españoles que consolidó bajo los Reyes Católicos, pero sus «monjes prietos» de rigurosa vida ya representaban un modelo espiritual para las conciencias más fervientes de Castilla (Martínez Sopena, 2004; Olivera, 2013b).

En tales condiciones, no es extraño que este retablo enfatice un dato habitual de los retablos: su sentido de memoria y propaganda. Mueven a reflexión, sobre todo, las claves simbólicas de su cuadro principal. Sentada en su trono y delante de un coro de ángeles cantores y músicos cuya silenciosa melodía realza la escena, la Virgen María sostiene al niño Jesús. A su alrededor, otros personajes se unen entre sí y con la pareja celestial mediante expresivos gestos. En pie y revestidos con los hábitos de las órdenes que promovieron, los santos Benito de Nursia y Domingo de Guzmán amparan al arzobispo y a Fernando de Antequera, piadosamente arrodillados. Al mismo tiempo, María impone la mitra a Sancho de Rojas y el Niño-Dios corona al rey de Aragón.

En las páginas anteriores se han destacado los estrechos lazos del infante-rey con el antes obispo de Palencia, así como su devoción mariana y su predilección por los dominicos. Ahora ambos, soberano de Aragón y primado de las Españas, reflejan en su doble coronación a lo divino una oportuna metáfora de su legitimidad: la Providencia cuyo auxilio solicitara Juan I de Castilla al fundar el monasterio, los había designado para cumplir sus altas funciones en el reino y en toda España. Por otra parte, al representarse bajo la protección del patrono de la casa, el arzobispo convalidaba su papel de comitente de la obra por el de beneficiario de las gracias espirituales de tan virtuoso lugar. En paralelo, y dado que el encargo debió ejecutarse después de su muerte en 1416, la imagen de Fernando de Antequera cobijada por Santo Domingo confirmaba una clave de su fortuna eterna.

Quizá esta escena podría interpretarse como resumen de los elementos simbólicos y políticos cuyas numerosas, muy variadas y por lo general breves secuencias escritas se han ido desgranando a lo largo de estas páginas. Me parece que sugiere diversas formas de memoria social, así como la posibilidad de articularlas.

\footnotetext{
${ }^{24}$ Este retablo fue sustituido por el que esculpió Alonso Berruguete, su obra maestra, que se terminó de montar en 1532 (hoy se puede contemplar en el Museo Nacional de Escultura de Valladolid). El primitivo fue trasladado a una de las capillas de la iglesia conventual. Corriendo el tiempo, el prior de San Benito lo cedió al pequeño monasterio de San Román de Hornija. Manuel Gómez Moreno, que lo conoció muy maltratado en este emplazamiento, consiguió que fuera entregado al Museo del Prado. Su última restauración data de fechas recientes.
} 
BIBLIOGRAFÍA

Alijo Hidalgo, Francisco (1983): Antequera y su tierra: 1410-1510, Libro de Repartimientos, Málaga, Arguval.

Alvar GaRCÍA DE SANTA MARÍA: Crónica de Juan II de Castilla, 1982, J. M. Carriazo Arroquia (ed.), Madrid, Real Academia de la Historia.

BAUTISTA, Francisco (2012): «Alvar García de Santa María y la escritura de la historia», en Modelos intelectuales, nuevos textos y nuevos lectores en el siglo XV. Contextos literarios, cortesanos y administrativos. Primera entrega, P. M. Cátedra (dir.), Salamanca, Universidad de Salamanca / Semyr, pp. 27-59.

Cancionero de Baena, 3 tomos, 1966, J. M. Azáceta (ed.), Madrid, CSIC.

CAÑAS GÁlveZ, Francisco de Paula (2016): «La casa del Infante Fernando de Castilla: corte, poder y representación político-institucional en el ocaso del medievo (13851408)», Boletín de la Real Academia de la Historia, CCXXIII, I, pp. 9-108.

Chronica Hispana saeculi XII. Pars II, Chronica Naierensi, 1995. J. A. Estévez Sola (S/cura et studio), Turhnout, Brepols.

CoBos RodríGuez, José Juan (2016): «Antequera (Málaga): de Madina al-Andalus a villa castellana», Edad Media. Revista de Historia, 17, pp. 197-224.

CORREA, Pedro (1999): Los romances fronterizos. Edición comentada, Manuel Alvar (prólogo), Granada, Universidad de Granada, 2 tomos.

Duque Herrero, Carlos (2006): Villalón de Campos. Historia y patrimonio artístico (Del siglo XIV al XVI), Palencia, Cultura y Comunicación.

EstePA DíEZ, Carlos (2003): Las behetrías castellanas, 2 vols, Valladolid, Junta de Castilla y León.

FERnANDEZ De LaRreA, Jon Andoni y Díaz De DuranA, José Ramón (2010): «Prefacio», Memoria e Historia. Utilización política en la Corona de Castilla al final de la Edad Media, J. A. Fernández de Larrea y J. R. Díaz de Durana (eds.), Madrid, Sílex, pp. 9-13.

GARCIA, Michel (2010): «Noticias del presente. Memoria del futuro. Escribir la historia de Castilla en 1400 y más adelante», Memoria e Historia. Utilización política en la Corona de Castilla al final de la Edad Media, J. A. Fernández de Larrea y J. R. Díaz de Durana (eds.), Madrid, Sílex, pp. 15-41.

GONZÁLEZ SÁNCHEZ, Santiago (2016): Los recursos militares de la monarquía castellana a comienzos del siglo XV: las campañas granadinas del Infante don Fernando: Setenil y Antequera (1407-1410), Madrid, Dykinson.

Information et Société en Occident à la fin du Moyen Âge. Actes du Colloque International tenu à l'Université du Québec à Montréal et à l'Université d'Ottawa (9-11 mai 2002), 2004, C. Boudreau, K. Fianu, C. Gauvard, M. Hebert (comp.), París, Publications de la Sorbonne.

LAdero QuesAdA, Miguel Ángel (2013): «Los Trastámaras de Castilla a la Corona de Aragón», en El Compromiso de Caspe (1412). Cambios dinásticos y constitucionalismo en la Corona de Aragón, M. I. Falcón (dir.), Zaragoza, Obra Social de Ibercaja, I, pp. 128-145. 
LÓPEZ ESTRADA, Francisco (1956): La conquista de Antequera en el romancero y en la épica de los Siglos de Oro, Sevilla, Diputación de Sevilla.

LÓPEZ ESTRADA, Francisco (1998): Poética de la frontera andaluza (Antequera 1424), Salamanca, Universidad de Salamanca.

Lorenzo Valla (2002): Historia de Fernando de Aragón, ed. esp. S. López Moreda, Madrid, Akal.

LUCAS DE TUY (ca. 1230/1525): Libro de los miraglos de sant Isidro arçobispo de Seuilla, Juan de Robles (trad.), Salamanca, Alonso de Porras, Lorenzo de Liondedei.

MACKAY, Angus (1988): «Los romances fronterizos como fuente histórica», en Relaciones exteriores del reino de Granada. IV Coloquio de Historia medieval andaluza, C. Segura Graíño (coord.), Almería, Instituto de Estudios Almerienses, pp. 273-285.

MARTín CEA, Juan Carlos (1991): El mundo rural castellano a fines de la Edad Media. El ejemplo de Paredes de Nava en el siglo XV, Valladolid, Junta de Castilla y León.

Martínez Sopena, Pascual (1977) El Estado señorial de Medina de Rioseco bajo el Almirante Alfonso Enriquez (1389-1430), Valladolid, Universidad de Valladolid.

MARTíNEZ SOPENA, Pascual (1999): «El señorío de Villavicencio: una perspectiva sobre las relaciones entre abadengo y behetría», en Aragón en la Edad Media, XIV-XV. Homenaje a la profesora Carmen Orcástegui Gros, vol. II, Zaragoza, Universidad de Zaragoza, pp. 1015-1025.

MARTíneZ SoPENA, Pascual (2004): «Reforma de los claustros y sociedad en la España de la Baja Edad Media», en «Das kommt mir spanisch vor» Eigenes und Fremdes in den deutsch-spanischen Beziehungen des späten Mittelalters, K. Herbers y N. Jaspert. Münster (eds.), Lit Verlag, pp. 531-564.

MenANT, François (2006): «Les transformations de l'écrit documentaire entre XII et XIII ${ }^{\mathrm{e}}$ siècles», en Écrire, compter, mesurer. Vers une histoire des rationalités pratiques, N. Coquery, F. Menant y F. Weber (dirs.), París, Editions Rue d'Ulm.

MontANer Frutos, Alberto, (2009): «El Pendón de San Isidoro o de Baeza. Sustento legendario y constitución emblemática», Emblemata. Revista aragonesa de emblemática, 15, pp. 29-70.

MuÑOZ GómEZ, Víctor (2016): Fernando «el de Antequera» y Leonor de Alburquerque (1374-1435). Una historia de poder en la Península Ibérica a fines de la Edad Media, Sevilla, Universidad y Ateneo de Sevilla. DOI: https://doi.org/10.12795/9788447221448

NiETo Soria, José Manuel (2012): «Fernando de Antequera, regente de Castilla», en La corona de Aragón en el centro de su historia, 1208-1458: El interregno y el Compromiso de Caspe, J. A. Sesma (dir.), Zaragoza, Grupo CEMA, pp. 293-314.

Olivera SERrano, César (2013): «La crisis dinástica portuguesa de 1385 y el Compromiso de Caspe. La experiencia personal y familiar de Fernando de Antequera», en El Compromiso de Caspe (1412). Cambios dinásticos y constitucionalismo en la Corona de Aragón, II, M. I. Falcón (dir.), Zaragoza, Obra Social de Ibercaja, pp. 584-589. DOI: https://doi.org/10.3989/aem.2013.43.2.11

Olivera Serrano, César (2013b). «Devociones regias y proyectos políticos: Los comienzos del monasterio de San Benito de Valladolid (1390-1430)», Anuario de Estudios Medievales, 43, 2, pp. 799-832. 
PelÁez RovirA, Antonio Miguel (2016): «La imagen fronteriza de Antequera en los textos andalusíes», Anaquel de Estudios Árabes, 27, pp. 151-167. DOI: https://doi.org/10.5209/rev_ANQE.2016.v27.47974

Reglero De LA Fuente, Carlos (1995): «El poblamiento del Noreste de la Cuenca del Duero en el siglo XV», Hispania, LVII, II, 190, pp. 425-493.

Reglero De La Fuente, Carlos M. (2008): Cluny en España. Los prioratos de la provincia y sus redes sociales (1073-ca. 1270), León, Centro de Estudios e Investigación «San Isidoro». DOI: https://doi.org/10.4000/cem.11145

VILLARROEL GONZÁLEZ, Oscar (2003): Las relaciones entre el arzobispado de Toledo y la Monarquía en tiempos de Juan II de Castilla (1406-1454), Toledo, Ayuntamiento de Toledo.

Fecha de recepción: 24 de abril de 2019

Fecha de aceptación: 2 de septiembre de 2019

$$
9
$$

